\title{
Response to Intervention (RTI) and Changes in Special Education Categorization
}

\author{
Kasandra Raben \\ Wabash and Ohio Valley Special Education District
}

\begin{abstract}
Justin Brogan, Mardis Dunham, and Susana Contreras Bloomdahl Murray State University
\end{abstract}

\begin{abstract}
Response to intervention (RTI) is used as a prerequisite to referring children for special education eligibility for learning disabilities (LD). RTI provides schools with a framework for helping students with learning challenges. In the United States, while the number of students receiving services through RTI has remained consistent, the overall number of students receiving some educational intervention through an alternate path has increased. The purpose of this study was to determine the influence that the RTI model had upon eligibility numbers in a large special education co-operative spanning 21 rural school districts in southern Illinois that represented 15,128 students. Each of the school districts maintained its own policies and procedures governing RTI implementation, special education referral, and special education eligibility. The study revealed that while the number of students with LD dropped significantly over the past decade, the numbers of children eligible for other disability categories increased in a similar proportion. This changing trend may be the result of several factors including changes in school district policy, parent advocates pressing for quicker paths to treatment, treatment providers shifting categories for a wide variety of reasons, or some yet unknown factor. These possible explanations suggest that family issues, time, finances, and procedural dynamics may play a role in the changing categorizations and should be better understood. Future studies should focus on the inclusion of more culturally and economically diverse students, within and outside the Unites States. Last, school district policies and RTI implementation procedures should be investigated to better uncover any potential relationship to this shifting data trend.
\end{abstract}




\section{Introduction}

Internationally, a number of countries utilize some method of multi-tiered student supports for students who require education evaluation and support services (Björn, Aro, Koponeen, Fuchs, \& Fuchs, 2016; Greenwood \& Kelly, 2017; Grosche \& Volpe, 2013; Musti-Rao, Hawkins, \& Tan, 2011). In the United States, prior to the Individuals with Disabilities Education Improvement Act (IDEA) of 2004, students with learning disabilities (LD) were typically determined eligible for special educational programming using a discrepancy between achievement and intellectual ability. The U.S. Department of Education in the mid-1970s included a discrepancy between achievement and ability as part of the criteria (Lichtenstein, 2014). However, this evaluation method has long been criticized in the literature for lacking scientific justification, relying too heavily upon psychometrically unsound assumptions, encouraging a wait-to-fail approach to evaluation, and over-identifying students with LD (Aaron, 1997; Fuchs \& Fuchs, 2017; Lichtenstein, 2014; Lyon et al., 2001).

With the passage of the IDEA in 2004, the U.S. Congress, heeding calls from a range of professional organizations (e.g., National Association of School Psychologists, 2003) and researchers to discontinue the ability-achievement discrepancy approach, provided a revised version that was seemingly improved over its predecessor (Berkeley, Bender, Peaster, \& Saunders, 2009; Fuchs \& Fuchs, 2006; Hale, Kaufman, Naglieri, \& Kavale, 2006; Lichtenstein, 2014). Specifically, the reauthorization provided an alternative means of identifying students with specific LD. Rather than relying on an ability-achievement discrepancy, IDEA allowed local educational agencies to consider the child's response to scientifically based instructional interventions as evidence of a LD (2004). This approach, referred to as response to intervention (RTI) and more generally as multi-tiered student supports, significantly changed how children with learning problems were identified and provided services.

RTI is considered a model for student-centred assessment, which primarily uses research-based methods and problem solving to address and identify learning difficulties. Furthermore, RTI's core components consist of the fidelity of instructional interventions, research-based interventions, continuous progress monitoring, universal screening, and the provision of high-quality classroom instruction (Berkeley et al., 2009; Brown-Chidsey, \& Steege, 2010). RTI presented educators with a promising framework for the early identification and prevention of behaviour and learning problems for struggling students. More importantly, RTI reform for special education provided students with learning difficulties the benefit of both intensive instruction and an accommodation component, which yields the best approach to early prevention. Moreover, RTI provided intervention options for struggling students in the general education curriculum. Students who are successful because of the interventions then are able to continue with the general education curriculum. However, for students for whom the interventions fail, alternative interventions would need to be implemented, including testing for special education eligibility (Fuchs \& Fuchs, 2006; Martinez \& Young, 2011). 


\section{Benefits of RTI}

RTI has the potential to solve numerous problems that the ability-achievement discrepancy model could not. It provides poorly performing students with individualized instruction that differs from the inadequate instruction to which they may have been exposed, thus further differentiating students who have true disabilities from students who perform poorly due to lack of proper education. Additionally, RTI could potentially lead to a reduction in inappropriate special education enrolments and referrals (Orosco \& Klingner, 2010).

Research over the past 15 years has demonstrated a range of benefits of RTI and multi-tiered student supports. Kashima, Schleich, and Spradlin (2009), for example, found in the schools they studied that had implemented RTI, over $80 \%$ of the children have achieved their levels of competency in the areas assessed. Additionally, O'Connor, Bocian, Beach, and Sanchez (2013), in a four-year longitudinal study conducted on the outcomes of $\mathrm{K}-3$ students who had access to RTI Tier Two intervention compared to those who were in general education, found a significant increase in reading achievement for those in RTI Tier Two intervention. Following the process of RTI identification, over time, referrals dropped, and those who were referred increased in eligibility, which provided a more culturally and linguistically diverse representation of students (O'Connor et al., 2013). Some researchers have attributed such trends to educators' training in RTI implementation, leading to better differentiation in instruction across tiers and improved student responsiveness to the interventions, thus decreasing the need for referrals to special education program placement (O'Connor et al., 2013).

RTI can be applied to other areas of education such social studies, mathematics, and science (Kashima, Schleich, \& Spradlin, 2009). More importantly, through early detection and identification of academic difficulties, RTI can better serve a large, diverse group of underachieving children who would otherwise experience delayed intervention that would increase the likelihood of debilitating problems throughout school (Hale, Kaufman, Naglieri, \& Kavale, 2006).

\section{Limitations of RTI}

Although RTI strives to provide students suspected of having LD the interventions that will assist them in improving their academic functioning, there are limitations to the model that can hinder student success. According to Vaughn, Zumeta, Wanzek, Cook, and Klingner (2014), "many students with LD do not make the academic progress needed to meet grade-level expectations and to succeed in postsecondary settings" (p. 90). In addition, a long-held criticism of RTI is its effectiveness in diagnosing specific LD, which excludes unexpected learning failure as part of the identification process. This issue could be due to the presence of above-average or average cognitive abilities in the students who are referred, as RTI does not take general cognitive ability into consideration in its decision making. As a result, learners who are particularly slow to catch up are often designated as students with LD (Greaves, Fitzgerald, Miller, \& Pillay, 2002; Kaznowski, 2004). 
Similarly, models of RTI consist of interventions that demonstrate only modest empirical validation, which provides results that present non-responsiveness, rather than the absence or presence of underachievement (Berkeley et al., 2009). According to Berkeley et al., RTI cannot differentiate students with LD from those with other disabilities such as attention-deficit/hyperactivity disorder, behavioural or emotional disorders, or intellectual disabilities (2009). Some of this inconsistency could be attributed to inconsistent policies and implementation efforts across the country (Fuchs, Fuchs, \& Compton, 2012; Pyle, 2011). Even with guidance from educational agencies, professional organizations, and researchers to schools, districts, and states about how to implement RTI as an early intervention system delivery, questions remain about RTI's effectiveness (Fuchs \& Fuchs, 2017). For example, a major criticism of RTI is that it does not take into consideration mitigating factors that students face in school, including those faced by socio-economically, linguistically, and culturally diverse student populations (Orosco \& Klingner, 2010).

In addition to these limitations, O'Connor, Freeman, and Witter (2012) noted that while RTI programs have been implemented throughout the country by a majority of schools, many are not seeing significant improvement in achievement or behaviour. Specifically, they indicated, "the effect sizes reported for research studies of RTI are less consistent than many of its supporters profess, and those studies reporting strong results are likely to have levels of treatment fidelity that are atypical" (p. 297).

Some of the disappointing weaknesses of RTI are attributed to a combination of poor buy-in, lack of training, and lack of administrative support for the general education teachers responsible for providing the tiered supports for struggling learners (Orosco \& Klingner, 2010; Werts, Carpenter, \& Fewell, 2014). Similarly, treatment fidelity has been a perennial problem (Noell et al., 2005; Wickstrom, Jones, LaFleur, \& Witt, 1998). If teachers are reluctant or unable to provide pre-referral interventions for children suspected of $\mathrm{LD}$, then a reasonable assumption is that they will not refer children for LD eligibility. Rather, these teachers will likely make a referral for other eligibility categories that do not require pre-referral interventions. There is some support for this postulation; according to the U.S. Department of Education (2016), there has been a nationwide growth of the number of students classified as having autism or an other health impairment (OHI) over the last decade, while the number of students in special education remained fairly consistent. This trend suggests the possibility that categorization for many students has only shifted from LD eligibility to other categories (Grice, 2002). Although the reasons for this are unclear, a case can be made that the shift in eligibility could be attributed to the fact that special education categories other than LD typically require less intensive documentation to support eligibility or that parents and teachers may simply be advocating for relatively "easy to obtain" accommodations for their students.

\section{Purpose of the Study}

A review of the literature reveals that many schools across the country have implemented RTI and are seeing positive results, particularly in regard to providing earlier intervention services (Berkeley et al., 2009; Lipka \& Siegel, 2010; O'Connor et 
al., 2012; Turse \& Albrecht, 2015). Despite the apparent widespread adoption of RTI, at the national level, the actual number of students identified with LD has remained rather stagnant while the number of children determined eligible in other categories has increased. This trend prompts the question of whether school referrals teams are simply referring children for categories other than LD that require less documentation of failed intervention efforts. The purpose of the current longitudinal study was to further explore changes in eligibility across several eligibility categories in a state that requires RTI interventions prior to referral for LD. The following hypotheses were identified. Hypothesis 1: The percentage of students identified as eligible under the LD category would decrease from years 2006-2007 to 2014-2015. Hypothesis 2: The percentage of students identified as eligible under autism, OHI, and developmental delay (DD) categories would increase between academic years 2006-2007 and 2014-2015.

\section{Methods}

\section{Participants}

Participant data used for this study were obtained from a special educational co-operative in southern Illinois. Participants included all students in the represented K-12 districts. This co-operative serves 21 school districts across 15 counties. Geographically, the area is largely rural, agriculturally driven, and 95.4\% Caucasian. Each school district was governed by its own respective school board and superintendent. The policies and procedures governing RTI implementation, special education referral, and special education eligibility were not uniform, but rather diverse, based on each district's policies.

\section{Procedures}

Institutional review board approval was received to obtain and publish nonidentifying school data used in this study. We obtained data from archives stored electronically at a large rural special education co-operative in southern Illinois. For the 2015-2016 academic year, there were 15,128 students in these districts, of which 19\% were receiving special educational services. For this study, we obtained each district's total school population and percentage of students receiving services for academic years 2003-2004 through 2014-2015 from the electronic archives and entered them into SPSS. Additionally, the percentage of the total special education population eligible for services under the LD, autism, OHI, DD, intellectual disability (ID), and emotional disability (ED) categories were entered in order to calculate the percentage represented in each. To test the two hypotheses, a series of paired samples $t$-tests were calculated using SPSS. A .01 level of probability was adopted as an indication of a statistically significant difference.

\section{Hypotheses}

First, it was hypothesized that the percentage of students identified as eligible under the LD category would decrease from years 2006-2007 and 2014-2015, since a 
failed RTI is required as part of the eligibility process for LD. RTI programs were implemented across all 21 districts in the co-operative under study during the 20072008 academic year. Students determined eligible for services under the LD category before the 2007-2008 academic year were not required to fail RTI prior to referral. Under these circumstances, the true effect of the benefits of RTI in reducing the number of students identified under this category were expected to decrease post-RTI mandate. Second, and consistent with national trends, it was hypothesized that the percentage of students identified as eligible under autism, OHI, and DD categories would increase between academic years 2006-2007 and 2014-2015. When RTI is required as a prerequisite to LD determination, other disability categories which do not require RTI could conceivably increase.

\section{Results}

The overall student population across the 21 districts for the 2003-2004 academic was 16,248 , of which $17.8 \%$ were receiving special educational interventions. The mean number of students per district in the 21 districts for the 2003-2004 academic year was $774(S D=579)$. For the 2014-2015 academic year, there were 15,128 students, $19 \%$ of whom were receiving services. The mean number of students per district in the 21 districts for the 2014-2015 academic year was $720(S D=532)$.

The percentage of all students with a disability identified as having a LD in 20062007 , the last year that RTI was not required, was 41.9\%. In 2014-2015, the last year that data were available (and 7 years after RTI was implemented), the percentage of students with LD was $28.9 \%$. Results of the paired samples $t$-test was statistically significant $(t=4.33 . d f=20, p=<.001)$, indicating that the number of students identified with LD dropped significantly from 2006-2007 to 2014-2015.

Next, comparisons in eligibility numbers across the different disability categories were conducted by comparing the percentages of the number of students served across the remaining disability categories over the past 9 years - that is, from 2006-2007 to 2014-2015 (see Figure 1 and Table 1). As seen in Figure 1, the number of children served under the categories LD, autism, OHI, and DD appeared to change the most over time (see Table 2). Again, paired samples $t$-tests were calculated and the .01 level of significance was employed. Regarding autism, the number of children served under this category rose from $1.9 \%$ to $4.1 \%$; this change was statistically significant $(t=3.17$, $d f=20, p=.005)$. Next, regarding OHI, the $t$-test $(t=1.79, d f=20, p=.088)$ revealed no statistically significant change from 2006-2007 to 2014-2015 academic years (although the percentage actually increased from $13.9 \%$ to $17.7 \%$ ). Regarding DD, results of the $t$ test were statistically significant $(t=6.59, d f=20, p=<.001)$. Here, the percentage of students receiving special educational programming for DD increased from $3.1 \%$ to $13.1 \%$. Next, students receiving services for an ID decreased from $5 \%$ to $2.9 \%(t=3.03$, $d f=20, p=.006)$. Lastly, although the percentage of students receiving services for an ED decreased from $5.3 \%$ to $4.3 \%(t=1.05, d f=20, p=.309)$, this difference was not statistically significant. 
Figure 1. Trend of Eligibility Numbers Across Six Categories from 2006-2007 to 2014-2015.

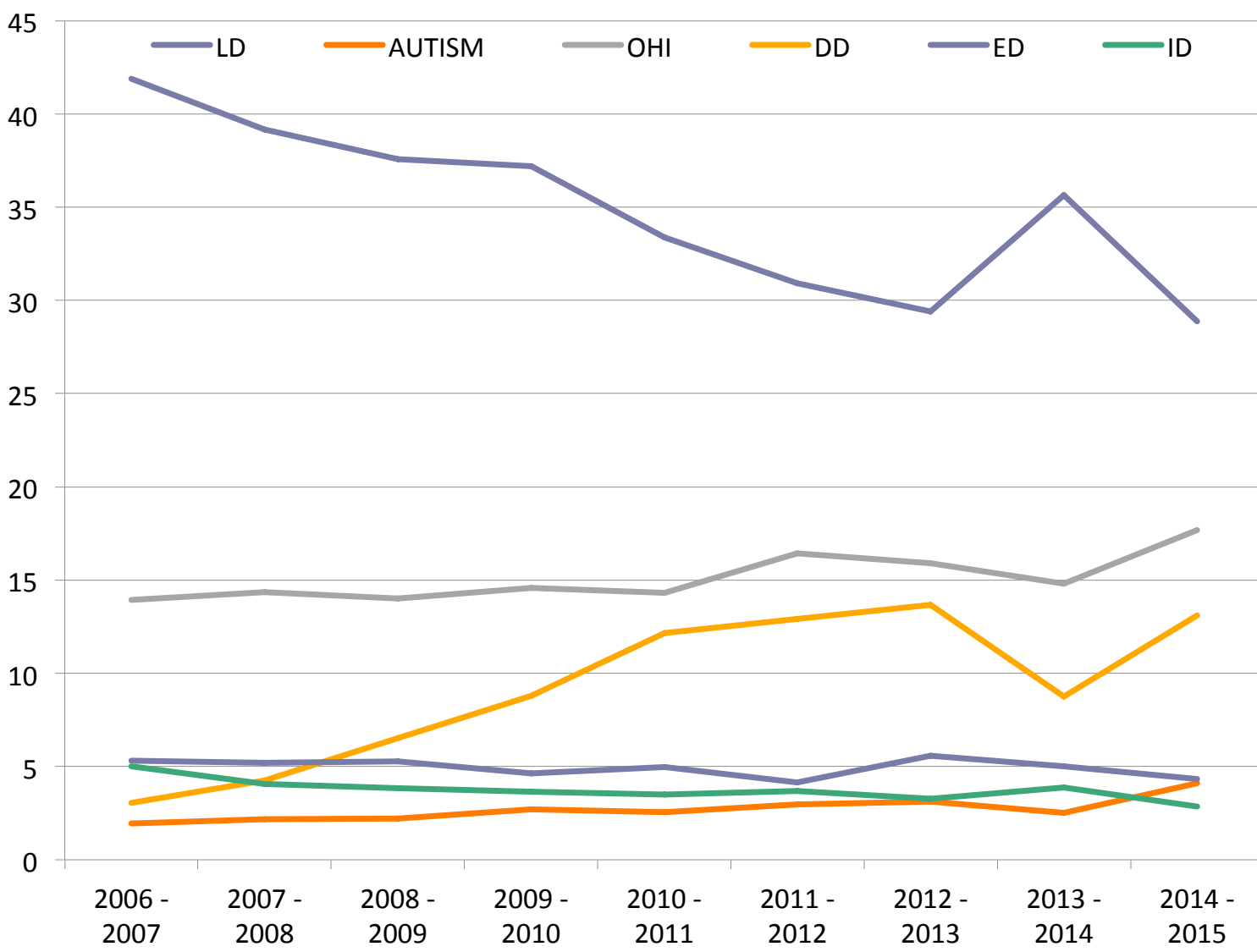

Note: $\mathrm{LD}=$ learning disabilities; $\mathrm{OHI}=$ other health impairment; $\mathrm{DD}=$ developmental delay; $\mathrm{ED}=$ emotional disability; ID = intellectual disabilities; .

Table 1

Average Percentage of Students Receiving Services, by Disability (Rounded)

\begin{tabular}{lccrrrrrrr}
\hline \multicolumn{1}{c}{ Academic Year } \\
Disability & $\mathbf{0 6 / 0 7}$ & $\mathbf{0 7 / 0 8}$ & $\mathbf{0 8 / 0 9}$ & $\mathbf{0 9 / 1 0}$ & $\mathbf{1 0 / 1 1}$ & $\mathbf{1 1 / 1 2}$ & $\mathbf{1 2 / 1 3}$ & $\mathbf{1 3 / 1 4}$ & $\mathbf{1 4 / 1 5}$ \\
\hline LD & 42 & 39 & 38 & 37 & 33 & 31 & 29 & 30 & 29 \\
Autism & 2 & 2 & 2 & 3 & 3 & 3 & 3 & 3 & 4 \\
OHI & 14 & 14 & 14 & 15 & 14 & 16 & 16 & 17 & 18 \\
DD & 3 & 4 & 7 & 9 & 12 & 13 & 14 & 12 & 13 \\
ED & 5 & 5 & 5 & 5 & 5 & 4 & 6 & 4 & 4 \\
ID & 5 & 4 & 4 & 4 & 4 & 4 & 3 & 3 & 3 \\
\hline
\end{tabular}

Note: $\mathrm{LD}=$ learning disabilities; $\mathrm{OHI}=$ other health impairment; DD = developmental delay; $\mathrm{ED}=$ emotional disability; ID = intellectual disability 
Table 2

Percentage and T-test Comparisons, by Disability

\begin{tabular}{lrrccc}
\hline Disability & $\mathbf{0 6 / 0 7}$ & $\mathbf{1 4 / 1 5}$ & $\boldsymbol{t}$ & $\boldsymbol{d f}$ & $\boldsymbol{p}$ \\
\hline LD & 41.9 & 28.9 & 4.33 & 20 & .000 \\
Autism & 1.9 & 4.1 & 3.17 & 20 & .005 \\
OHI & 13.9 & 17.7 & 1.79 & 20 & .088 \\
DD & 3.1 & 13.1 & 6.59 & 20 & .000 \\
ED & 5.3 & 4.3 & 1.05 & 20 & .309 \\
ID & 5.0 & 2.9 & 3.09 & 20 & .006 \\
\hline
\end{tabular}

Note: $\mathrm{LD}=$ learning disabilities; $\mathrm{OHI}=$ other health impairment; $\mathrm{DD}=$ developmental delay; ED = emotional disability; ID = intellectual disability.

\section{Discussion}

The results of the current study revealed a $1.2 \%$ increase in the number of students served in special education in the districts under study over the last 9 years, suggesting that the need for services has slightly increased over time. This increase is especially important to note because these districts experienced a $1.5 \%$ decrease in enrolment. There was a significant drop in the number of students identified with LD in this co-operative. This change is consistent with the national trend (U.S. Department of Education, 2014) and Kreider's research (2010), in which the number of students identified with LD dropped after RTI implementation. However, it is unknown whether the drop in numbers is due to the effectiveness of RTI or there are other explanations. For example, results of this study also showed an increase in the number of students eligible under the categories of autism, OHI, and DD. In fact, the increase in these other categories was similar to the decrease in the percentage of children served for LD and ID. Specifically, while the percentage of students with LD and intellectual disabilities dropped by $16 \%$ and $4 \%$ respectively, the percentage of students identified with autism, OHI, and DD increased by $6 \%, 11 \%$, and $3 \%$, respectively. Child Find statistics provided by the U.S. Department of Education (2014) yielded similar results, demonstrating nationwide growth of the number of students classified as having autism or OHI over the last decade, while the number of students in special education remained fairly consistent. This data suggests the possibility that categorization for many students has shifted from eligibility based on LD to other categories. One explanation for the shift in the numbers of children eligible for services across other categories could be policy changes that have mandated failed RTI efforts prior to referral for special education services for those children suspected of having a LD - thus, the RTI efforts were effective for those children with LD. On the other hand, the shift could be attributed to the fact that special education categories other than LD require far less documentation to support eligibility and that struggling students were simply referred for eligibility under another category, a suggestion posed by Grice (2002). For example, in Illinois, a student can qualify for services under the categories of autism or OHI with a medical diagnosis and documentation from the teacher, if the student is struggling either academically or behaviourally. Furthermore, a student can be classified as developmentally delayed with any pertinent standardized score that falls in the below 
average range for its respective domain, without any required documentation of a lack of improvement over time. Though documentation of student progress is recommended along with each intervention, it is not required for any eligibility other than specific learning disability in Illinois (Illinois State Board of Education, 2012). Last, the change in categorization could be accounted for in better training in the identification and diagnosis of all categories, which may indicate a move toward more precise diagnosis. This shift would potentially lead to better targeted interventions. Regardless of the precise reason for the change in categorizations, the data indicate that a change has occurred.

The results from this study support the notion that RTI is effective in reducing the number of children eligible for LD. However, because the percentage of students in several other categories actually increased, there remains another, yet to be determined, answer for why OHI categories have increased. One possible reason is that other categories, such as autism, OHI, and DD are becoming favoured because they require much less documentation to support eligibility from an educational standpoint. This possibility is one defensible interpretation of the data, primarily because there were no other changes in the law governing referrals and because the proportion of children served actually increased while the entire population of children in these schools decreased. Specifically, the percentage decrease in children served with LD was similar to the percentage increase in children served in other categories. If RTI efforts were effective, theoretically, there should have been a drop in the LD percentage only, with no other changes in percentage in other categories. The trend in eligibility numbers in this co-operative are similar to those seen across the United States (U.S. Department of Education, 2014). It could be that parents have advocated for children with academic problems to be served under other, more easily documented categories of special education in order to obtain services faster or to avoid providing lengthy interventions prior to referral. Similarly, it has been argued that limited resources, limited staff, and burdensome time commitments hinder RTI implementation (Darling-Hammond \& Bransford, 2005; Werts et al., 2014). Therefore, it is plausible that for general education teachers, who already have numerous general education responsibilities, the idea of providing special educational interventions can be daunting.

There is another broader question, not directly addressed in this study regarding eligibility: Does the specific eligibility category matter, provided the student receives necessary services? The categorization problem may become fully realized when those children who actually have a LD, but served under another category, apply for and are denied accommodations and services at the post-secondary level, either for college or vocational rehabilitation. Similarly, because state and federal funding is based upon the number of children across the different eligibility categories, this funding could now be based upon misleading data, which could result in the hiring of teachers to address the needs of special education students other than LD, resulting in the hiring of teachers who are ill-prepared to actually work with students with learning problems.

When considering the ideas described previously, school districts should consider the use of data collection methods and intervention programs that are uniform and standardized and that are implemented in tandem with daily classroom activities. Providing school personnel with the tools, training, and supports to make intervention and progress monitoring easier and more convenient should increase the likelihood of 
good data collection. Similarly, another factor to consider is the types of educators implementing the interventions and collecting the data. Naturally, a behaviourist may take a more behavioural approach when collecting and interpreting data, while a reading specialist might look more closely at specific areas of reading deficits rather than focusing only on the fact that a student is not reading at grade level. A special educator with training in behaviour disorders might guide RTI efforts differently than a paraeducator. For this reason, it would be beneficial for school districts to consider educational backgrounds of RTI coordinators and consultants when selecting RTI teachers and interpreting data in regard to making eligibility determinations.

\section{Conclusions}

This research article looked at trends in special education categorization data at an educational co-operative with more than 15,000 students. The results of this study demonstrated two significant changes in special education categorization data. First, that students identified as eligible under the LD category had decreased. Second, that the percentage of students identified as eligible under autism, OHI, and DD categories had increased. Results demonstrate a clear shifting in special education categorization. This changing trend may be the result of several factors including district policy changes, parent advocates pressing for a shorter route to treatment, providers shifting categories for a wide variety of reasons, or some yet unknown factor. Nonetheless, the process for analyzing this change in data is one important aspect of research to demonstrate the continued efficacy of multi-tiered student support programs.

\section{Limitations}

This study, like all studies, has limitations that can hinder generalization; some limitations are geographic, and some are procedural or policy related. First, the data for this study were obtained from a special education co-operative in southern Illinois. This co-operative, which serves 21 school districts across 15 counties, is largely rural, agricultural, and Caucasian. As a result, the findings may not generalize to the remainder of the state, the region, or other countries. Second, these 21 school districts are governed by 21 different school boards and school superintendents. Given such governance, the policies and procedures governing RTI implementation, fidelity checks, special education referral, and special education definitions and eligibility are not uniform but rather diverse. Even though there was diversity among these school districts, they were all geographically located in the same area and were governed by the same U.S. and state laws. For example, each district is responsible for determining how RTI and fidelity checks are implemented and how teachers adjust their teaching in response to tiered data collection efforts. So, while the large sample size may help with generalizability of the findings, it actually hinders the ability to discern how RTI and fidelity were provided prior to referral because of the highly individualized and heterogeneous nature of the districts vis-à-vis RTI. Third, and again because of the heterogeneous nature of the districts in terms of RTI procedures,

there was no way to determine whether the decrease in LD eligibility was due to a lack of referral for LD eligibility, to the effectiveness of RTI, or to some other procedural or personnel factors (or a combination of all three). Additionally, it is important to point out 
the "catch-all" nature of OHI (see Grice, 2002) and the fact that students with OHI (the category typically used for children with attention-deficit/hyperactivity disorder) are required to have behaviour goals and not academic goals. Essentially, eligibility for $\mathrm{OHI}$, and indeed for autism and DD is easier to obtain, both from the teacher's perspective and the school's perspective. Lastly, issues of treatment fidelity have plagued intervention efforts in the past (see Forman \& Burke, 2008; Noell et al., 2005; Wickstrom et al., 1998). Without data specifically addressing this issue, it is difficult to determine whether interventions for special LD prior to referral for eligibility may have played a role in decreasing the numbers, or if the requirement that interventions prior to referral must be in place may have prevented some referrals. This possible explanation is not intended to be accusatory, but rather suggests that personnel issues, time, and procedural dynamics may play a role and should be considered.

\section{Recommendations for Future Research}

Findings from this study suggest further analysis of the national data is needed in order to generalize the results across the entire population of students being referred for special education. Expanding this research across the state and region (or even country) would provide researchers the opportunity to explore whether or not these results are becoming a trend. Additionally, a more diverse population of students would help with generalizability. The population of students included in this study were primarily Caucasian and from rural, largely impoverished districts. A more economically diverse population would help with understanding and generalizing the results as well. For example, it could be that lack of funding could be influencing these findings. Another consideration for future research should include assessment of school districts and their policies for RTI implementation, special education referral, and special education eligibility procedures to determine how differences among school districts in implementing RTI procedures affects the number of students eligible under specific categories. It would also be helpful to examine the difference in the number of referrals made versus the number of students found eligible across districts. Finally, to address concerns with unknown treatment fidelity, future research is recommended to examine each district's RTI procedures with a focus on average student time spent on researchbased interventions and small-group size comparisons across districts.

\section{References}

Aaron, P. (1997). The impending demise of the discrepancy formula. Review of Educational Research, 67, 461-502. doi:10.3102/00346543067004461

Berkeley, S., Bender, W., Peaster, L., \& Saunders, L. (2009). Implementation of response to intervention. Journal of Learning Disabilities, 42(1), 85-95. doi:10.1177/0022219408326214

Björn, P., Aro, M., Koponen, T., Fuchs, L., \& Fuchs., D. (2016). The many faces of special education within RTI frameworks in the United States and Finland. Learning Disability Quarterly, 39(1), 58-66.

Brown-Chidsey, R., \& Steege, M. W. (2010). Response to intervention: Principles and strategies for effective practice. New York, NY: Guilford.

Darling-Hammond, L., \& Bransford, J. (Eds.). (2005). Preparing teachers for a changing world: What teachers should learn and be able to do. San Francisco, CA: Josey-Bass. 
Forman, S. G., \& Burke, C. R. (2008). Best practices in selecting and implementing evidence-based school interventions. In A. Thomas \& J. P. Grimes (Eds.), Best Practices in School Psychology V (pp. 875-886). Bethesda, MD: National Association of School Psychologists.

Fuchs, D., \& Fuchs, L. (2006). Introduction to response to intervention: What, why, and how valid is it? Reading Research Quarterly, 41(1), 93-99. doi:10.1598/RRQ.41.1.4

Fuchs, D., \& Fuchs, L. (2017). Critique of the national evaluation of response to intervention: A case for simpler frameworks. Exceptional Children, 83(3), 255-268.

Fuchs, D., Fuchs, L., \& Compton, D. (2012). Smart RTI: A next generation approach to multilevel prevention. Exceptional Children, 78, 263-279.

Greaves, D., Fitzgerald, A., Miller, G., \& Pillay, B. (2002). Diagnosis and program outcomes for students who learn differently. Australian Journal of Language and Literacy, 25(3), 64-79.

Greenwood, J., \& Kelly, C. (2017). Implementing cycles of assess, plan, do, review: A literature review of practitioner perspectives. British Journal of Special Education, 44(4), 394-410.

Grice, K. (2002). Eligibility under IDEA for other health impaired children. School Law Bulletin, Summer, 7-12.

Grosche, M., \& Volpe, R. (2013). Response-to-intervention (RTI) as a model to facilitate inclusion for students with learning and behavior problems. European Journal of Special Needs Education, 28(3), 254-269.

Hale, J., Kaufman, A., Naglieri, J., \& Kavale, K. (2006). Implementation of IDEA: Integrating response to intervention and cognitive assessment methods. Psychology in the Schools, 43(7), 753-770. doi:10.1002/pits.20186

Illinois State Board of Education. (2012). Illinois special education eligibility and entitlement procedures and criteria within a response to intervention (RTI) framework (Guidance document 12-04). Retrieved from https://www.isbe.net/Documents/sped_rti_framework.pdf

Individuals with Disabilities Education Act, 20 U.S.C. § 1400 (2004). Retrieved from https://sites.ed.gov/idea/

Kashima, Y., Schleich, B., \& Spradlin, T. (2009, June). The core components of RTI: A closer look at evidence-based core curriculum, assessment and progress monitoring, and data-based decision making (Special report). Bloomington, IN: Center for Evaluation \& Education Policy. Retrieved from ERIC database (Doc. ED531828), www.eric.ed.gov

Kaznowski, K. (2004). Slow learners: Are educators leaving them behind? NASSP Bulletin, 88(641), 31-45. doi:10.1177/019263650408864103

Kreider, T. E. (2010). The effects of response to intervention implementation on special education referral and identification rates (Doctoral dissertation). Retrieved from ERIC database (Doc. ED513564), www.eric.ed.gov

Lichtenstein, R. (2014). Best practices in identification of learning disabilities. In P. Harrison \& A. Thomas (Eds.), Best practices in school psychology: Data-based and collaborative decision making (pp. 331-354). Bethesda, MD: NASP.

Lipka, O., \& Siegel, L. (2010). The improvement of reading skills of L1 and ESL children using a Response to Intervention (RTI) model. Psicothema, 22(4), 963-969.

Lyon, G., Fletcher, J., Shaywitz, S, Shaywitz, B., Torgesen, J., Wood, F., ... Olson, R. (2001). Rethinking learning disabilities. In C. E. Finn, Jr., A. J. Rotherham, \& C. R. Hokanson, Jr. (Eds.), Rethinking special education for a new century (pp. 259-287). Washington, DC: Thomas B. Fordham Foundation.

Martinez, R., \& Young, A. (2011). Response to intervention: How is it practiced and perceived? International Journal of Special Education, 23, 44-52. 
Musti-Rao, S., Hawkins, R., \& Tan, C. (2011). A practitioner's guide to consultation and problem solving in inclusive settings. Teaching Exceptional Children, 44(1), 18-26.

National Association of School Psychologists. (2003). NASP Recommendations for IDEA reauthorization: Identification and eligibility determination for students with specific learning disabilities. Bethesda, MD: Author. Retrieved from http://www.nasponline.org/assets/documents/Research\%20and\%20Policy/Advocacy\%20Res ources/LDRecs_042803.pdf

Noell, G., Witt J., Slider, N., Connell, J., Gatti, S., \& Williams, K. (2005). Treatment implementation following behavioral consultation in schools: A comparison of three follow-up strategies. School Psychology Review, 34, 87-106.

O’Connor, E. P., Freeman, E., \& Witter, J. (2012). District-level considerations in supporting and sustaining RTI implementation. Psychology in the Schools, 49(3), 297-310. doi:10.1002/pits.21598

O'Connor, R., Bocian, K., Beach, K., \& Sanchez, V. (2013). Special education in a 4-year response to intervention (RTI) environment: Characteristics of students with learning disability and grade of identification. Learning Disabilities Research \& Practice, 28(3), 98-112.

Orosco, M. J., \& Klingner, J. (2010). One school's implementation of RTI with English language learners: "Referring into RTI." Journal of Learning Disabilities, 43(3), 269-288. doi:10.1177/0022219409355474

Pyle, A. (2011). Considering coherence: Teacher perceptions of the competing agendas of RTI and an existing special educational model. Exceptionality Education International, 21(3) 66-81.

Turse, K., \& Albrecht, S. (2015). The ABCs of RTI: An introduction to the building blocks of response to intervention. Preventing School Failure, 59(2), 83-89. doi:10.1080/1045988X.2013.837813

U.S. Department of Education. (2014). 1995-2013 Annual reports to Congress on Individuals with Disabilities Education Act. U.S. Department of Education Office of Special Education Programs IDEA Static Tables. Retrieved from https://www2.ed.gov/about/reports/annual /osep/2014/index.html

U.S. Department of Education. (2016). Digest of Educational Statistics, 2015 (NCES 2016-014). National Center for Education Statistics. U.S. Department of Education. Retrieved from https://nces.ed.gov/pubs2016/2016014.pdf

Vaughn, S., Zumeta, R., Wanzek, J., Cook, B., \& Klingner, J. (2014). Intensive interventions for students with learning disabilities in the RTI era: Position statement of the division for learning disabilities council for exceptional children. Learning Disabilities Research \& Practice, 29(3), 90-92. doi:10.1111/ldrp.12039

Werts, M., Carpenter, E., \& Fewell, C. (2014). Barriers and benefits to response to intervention: Perceptions of special education teachers. Rural Special Education Quarterly, 35(2), 3-11. doi: $10.1177 / 875687051403300202$

Wickstrom, K. F, Jones, K. M, LaFleur, L. H, \& Witt, J. C. (1998). An analysis of treatment integrity in school-based behavioral consultation. School Psychology Quarterly, 13, 141-154. doi: $10.1037 / \mathrm{h} 0088978$

\section{Authors' Note}

Correspondence concerning this article should be addressed to Justin Brogan at Murray State University, 3201 Alexander Hall, Murray, KY, 42071, U.S.A. Email: jbrogan@murraystate.edu 